\title{
Socio-discursive Interactionism: An Epistemological Frame for Language Practices and Communication Practices
}

\author{
María Susana Felli \\ National University of La Plata, La Plata, Argentina
}

\begin{abstract}
The present work is part of the research we have been doing for our PhD in Communication (School of Journalism and Social Sciences, National University of La Plata). In order to delimit the scope of this paper, we start from a state of the art centered in the relations, similarities, and differences between language and communication practices. The thesis of this work takes into account two aspects: On one hand, what and which are the language practices associated with communication, analyzed in the frame of socio-discursive interactionism; on the other hand, how these practices emerge in the courses of study in Arts and Social Communication as objects of study and modes of social and/or communicative intervention. We worked with prescriptive curricular perspective and with language practices and communication practices, where the epistemological fields are still being created. Among other aspects this problem is related to the study of the traditional training in power spaces, knowledge over language from the disciplinary field and in the syllabus of the courses of study, and in the traces, the importance and the consequences of this knowledge in teachers' training. This first approach to the state of the art is supposed to be a first sample and analysis of how the object of study has been investigated, the perspectives to think about it, and their methodologies, categories, units of analysis, etc. which have been adopted in these previous works.
\end{abstract}

Keywords: language practices, communication, teachers’ training, socio-discursive interactionism

Texts and/or discourses constitute the only human manifestations empirically verifiable of human communicative actions.

—Jean-Paul Bronckart

\section{Introduction}

The present work is part of the research work that we have been doing as PhDs in Communication, School of Journalism and Social Sciences, National University of La Plata. In order to delimit the scope of this paper, we start from a state of the art centered in the relations, similarities, and differences between language and communication practices. We work on prescriptive curricular perspectives in language and communication practices, in which the epistemological fields are still being created. In fact, from language practices we witness a period of epistemological crisis when "teaching language" means participating/constructing in and from practices and abilities which belong to social life (General Bureau of Culture and Education, 2008).

As mentioned above, we are going to focus, in particular, on theoretical frames for the analysis of the relation

Susana Felli, professor, PhD, School of Journalism and Social Sciences, National University of La Plata. 
between the courses of study: Language and Literature Teaching and Communication Teaching. This paper is a theoretical work that from the theoretical-methodological frame of socio-discursive interactionism tries to explain how university and higher education formation in the said courses of study is shaped, that is, from which previous ideas. On the one hand, Language and Literature Teaching course is markedly linguistic-oriented, and on the other hand, communication theories are combined with semiotic studies and/or cultural studies. All this considered, we find ourselves in a complex epistemological field from the point of view of communication.

One of the topics that is of great importance to this work and becomes the central axis of it is the analysis of the conceptions of language that govern and give rise to Language and Literature teachers and Communication teachers' training. In order to study this central aspect, we start from different questions which are related to it and that, in fact, arise after a close examination of syllabus in full force and effect for the previously mentioned courses of study. The topics in common for both courses of study revolve around terms such as: language/written language, language/spoken language, language/language practices, language as an object of study, language as a professional device, writing as an instrument or as an object of study, relations between language and communication, among others.

In order to tackle these topics, it is fundamental to work on the different conceptions of language that are derived from each theoretical position. According to researcher Dora Riestra (National University of Río Negro),

The conception of language that we chose will be determinant when it comes to define concepts and methodological processes as regards the teaching point in language didactics; that is why we need to delimit what we understand as language and how we understand its relation with other languages, given that its consequences will be of great importance when drawing up a didactic design for the teaching of language at any level of education. (Riestra, 2010, p. 130)

Very briefly, we are going to delimit the object of study that we are going to work on in this paper. It includes the relations between language practices and communication practices. These are areas of social sciences which hitherto have been disconnected in the syllabus, except for a few cases. Besides, our work details the path we have been going along in relation to our communication students' training at the School of Journalism and Social Communication of the National University of La Plata and to the teachers' training in institutions belonging to the General Bureau of Culture and Education.

Specifically, we delimit the scope of this paper not only from the curricular/didactic point of view but also from the communicational one in terms of socio-cultural practices. We consider that the epistemological border consists in stop looking at the object as something abstract and start taking into account social processes from people's viewpoint for the construction of knowledge. In other words, we leave behind an abstract objectivism and adopt a subjectivism that creates a viewpoint from which we can construct and set up the object (Bourdieu, 2001). Language is one of those inherent modes that give account for subjectivities, shaping them at the same time. In the light of what has been said, we claim that a researcher modifies and constructs practices when he positions himself from a particular theoretical position. This approach guides us towards a scientific practice with the "criticality" inherent to knowledge.

\section{Language/Actions/Training}

Training in language supposes critical theoretical positions with respect to the questioning and interpretation of reality and knowledge. As the object is multidisciplinary, its study too has to be done within the disciplines that 
are involved. Higher education and university training in Language and Literature and in Communication share the characteristic that they both consider language constitutive; this being so as language gives rise to both of them, and both courses of study involve new modes of intervening in the educational and social reality in a formal education environment or otherwise.

In this first approach to the topic, we try to define which features both courses of study have in common and we take as a starting point the syllabus for them which are in full force and effect (and their revised versions also) and we found “language democratization” (National Institute of Teachers' Training, 2012). The epistemic character that is attributable to language, as a mode of intervening on reality, gives training a resignification of the criteria when it comes to think of and draw up didactic designs to train professionals in academic as well as social practices.

As regards practices, the notion "language practices" is rooted in the studies on "language activities" done by linguist A. Culioli in the 1970s. The term is related to social practices, its study includes practices of production, reproduction, and transformation. Language practices are constituted and at the same time constitute given that they produce effects on social aspects to change them (Charaudeau \& Maingueneau, 2005). In discourse analysis studies, the concept "language practices" is a synonym of "discursive practices" (Foucault, 1979), which means “language or verbal activities”, spoken as well as written. Linguist D. Maingueneau (2005) affirmed that this conceptualization combines discursive communities that produce utterances with the content form, the social organization modes, and the circulation net of the utterances.

From the frame of socio-discursive interactionism, practices are related to the pursuit of specificity in sciences. That is why these studies are presented as a research megaprogram and not as an interdisciplinary study. The methodology is "globally comprehending” (Bronckart, 2004) and it has three gradual instances, namely: (1) analysis of interaction social world/intertextualities from an almost sociological frame, (2) text analysis, and (3) analysis of mental operations implied in textualization from a rather psychological frame. This analysis goes from the social to the individual and it goes along with Voloshinov's (1929/2009) language philosophy and Bajtín's (1982) studies. We refer to Bronckart’s studies, in particular his empirical works that have constituted a theoretical and methodological frame of study for the processes implied in textualization. "Textualizing” is, in this approach, a product of language activity and it makes evident how one learns to construct texts.

Textualization processes have their origin in the concept of "language" as a distinct unit of language, language seen from philosophy and language psychology. In this sense, language in interactionism is similar to Saussurean dichotomy langue/parole because the latter includes an individual aspect and a social one, it has several forms and it is heterogeneous (Saussure, 1984). Langue is related to human capacity, as a product of human activity throughout time (cf. Coseriu, 1977). Notwithstanding, Bronckart disagrees with Saussure's concept of langue given that the latter can never be homogeneous but changing and dynamic instead, which means that it is rather close to Saussure's "linguistic sign”. A sing, in this frame of study, is product of the negotiation process that changes representations that are individual, idiosyncratic and makes them representations that are communal, transferable. Then, from the point of view of interactionism, language is an activity that relates a person in a certain time of the history with its community. The relation mentioned is one of the languages with social agents' actions.

As Dora Riestra (2011) presented it: 
From our socio-discursive interactionist approach, as regards language teaching, the re-interpretation of Vygotsky and Saussure is the starting point for the elaboration a language didactics, which are deviated from the representationalist language conception in its various forms, namely the logical-grammatical, the functionalist, the one of typologies and the cognitivist-biologicist as well as computational. That is to say, the state of the art of human knowledge in its complexity does not allow us to impose clear-cut divisions; it rather obliges us to establish connections between disciplines in order to understand human "languaging” (lenguajear, as Chilean Humerto Maturana defined with precision). From this approach, with the didactic design that is drawn up in the line: USE-MEANING-FORM, we aim to establish the approaching to texts as semiotic objects which are contextualized, a fact which is necessarily based in Vigotsky's concept of relations between the interpsychic and interpsychic and in Voloshinov's dialogical concept of genre with the later contributions of Bronckart to this interactionist conception. (p. 139)

Following the approach of Bronckart's last studies, very briefly, his studies are divided according to three different instances: (1) focused on acting-action-activity, organizing psychological processes with sociological ones; (2) exhaustive language analysis and its effects in the mind; and (3) study of the general training processes, especially education at school.

To ponder on human action in its different levels and dimensions, Bronckart (2007) proposed a number of steps for analyzing the process integrally.

(1) The analysis of the collective activities, particularly the ones related to work. They are the first element because they constitute the frame in which the essential of the relations of the individual and the environment are organized and mediated.

(2) The analysis of the emergency and working conditions of social formations in their sociological and political dimensions. They are the medium by which human activity is organized according to the contexts - physical, economic, historical. These gatherings give rise to norms, institutions, rules, and values.

(3) The analysis of the properties and effects of texts and discourses as a manifestation of human communication activity (Communicative action, Habermas, 1987).

Functionally, this activity is a mechanism used by human beings to agree on contexts, objectives, and ways of realizing complex activities (Language activities are used to explain, plan, and evaluate).

As regards structure, verbal actions are organized in embedded levels. Briefly:

(1) Texts: spoken or written global communication unities that are created depending on the type of non-verbal activities that people are engaged in and on the socio-historical conditions of its elaboration (Discursive formation, Foucault, 1979). Texts are grouped in different genres that are labeled socially, that is to say, they are recognized as belonging to and/or adapted to a given communicative situation.

(2) Discourse types: Every text is made up of more or less variable discourse types. They are linguistic forms characterized by restrictions in the selection of morpho-syntactic unities (Bronckart, 2007, pp. 26-30).

On the most relevant findings of the socio-discursive interactionism is thinking about human activities, language being one of them. This epistemological choice has an impact on language studies and language training studies. From the concept of activity of Leontiev, Bronckart understands acting as a generic term that refers to every active behavior of an organism. As Dora Riestra (2011) affirmed:

If all species present social behavior and communicative actions (aimed at their peers), human is apparently the only one that resorts to verbal communicative actions as they create signs, organized at the same time in texts, which allow them to construct a gneosological space; that is to say, a world of knowledge that does not depend on individual life circumstances, but one that can makes it possible for knowledge to be accumulated throughout history instead. (p. 152) 
The implications of this approach place "the passing from textual action to linguistic reflection" (Riestra, 2011) in front of two axis of knowledge: praxeology and epistemological. This passing becomes relevant when it comes to the construction of didactic designs and linguistic systemization from language sciences.

\section{Towards a State of the Art}

Apart from what has been said, continuing with this research approach, the background works that face the problem that we are interested in have been selected by either theoretical-methodological proximity (in the frame of socio-discursive interactionism and communication/language relations) or because they have the same object of study (teachers' training in Communication and/or Language and Literature), or by the treatment of the conceptualization (working on human communication/language and/or its impacts).

(1) Alves dos Santos Nascimento, Hiliana, \& Aguiar, Marigia Ana. (2010). "Interaccionismo socio-discursivo, ensino de lengua e os géneros textuais”. Published at: Víctor M. Castel and Liliana Cubo de Severino, Editores. Word renewal at Argentina's Bicentenary. The colors of the linguistic look (Proceedings of SAL Congress). Mendoza, Editorial School of Arts, National University of Cuyo. Chapter 12, Pages 109-115. Available at http://mendozaconicet.gob.ar/institutos/incihusa/ul/csal12/Castel_y_Cubo,_Editores_\%282010\%29.htm

These Brazilian researchers worked on the concept of textual genres form socio-discursive interactionism, which, for us, is just one aspect of the problem. They refer to texts and not to discourses, which is a central distinction between this work and ours. More specifically, they approach, among other aspects, how to produce, teach, and interpret texts in Portuguese language teachers' training according to socio-discursive interactionism: Bronckart, Bajtin, and Vigotsky (1934/2010). They also take into account the contributions of Schneuly (2004), Dolz (2010), and Marcuschi (2008), which is important for us as regards the frame of study we have selected.

We disagree with these researches as regards the central function of curricular aspects in the training of teachers of Communication and of Language and Literature. The questions we try to answer as regards our object of study are related to: the place of language practices in the training processes, their common aspects, their properties which are similar, different, contradictory, and non-inclusive of teachers' training. Apart from that, could they be integrated? Should all teachers have the same training? In which aspects could not they be combined? Or, if they can, in which ones and how?

The authors claim that in Brazil, from 1960 onwards, there have been a number of alterations in the education policies that present a professional model prone to work with a new vision (social, political and changing, with social inclusion as a priority). This situation obliged the Ministry of Education to take official action. The same situation is taking place in our country with the changes of Curricular Design in the period from 2007 up to the present.

Among their conclusions, they propose the teaching of reading and writing texts in Portuguese in the classroom from genres which belong to real communicative situations. We consider that these situations are one aspect of the complex problem related to teachers' training.

(2) Castillo Iglesias, Lucía Fernanda, \& Soto Vergara, Guillermo. (2012). "The role of intersubjectivity in human communication evolution and in language emergence”. Presentation at the Conference Postal at University of the Serema, Chile. Seventh National Meeting of the Discourse Studies Latin-American Association. 23/7/2012. Available at http://congresos.userena.cl/index.php/ALED2012/Aled2012/paper/view/95;

http://prezi.com/nam0zkuzojts/aled-2012-castillo-soto/ 
This research work tries to analyze the emergence of the language faculty in relation to the evolution of cooperative human interaction and intersubjectivity construction. These authors present the emergence of the language faculty in a context in which the social communication and intersubjectivity construction were determinant. They start from the previous development of a "cooperative infrastructure" (Tomasello, 2008) for human communication, on which the success of the interaction would depend, in pragmatic terms. As a consequence, they study abilities in the frame of the Theory of the Mind and also the capacity for sharing intentions.

This study is different from ours given that in no way socio-discursive interactionism can be considered cognitivist. On the contrary, it would be interesting to analyze how that nature impedes the existence of a Human Science or a Culture Science, which is what we are going to focus on in our thesis. Thinking on a cooperative infrastructure is thinking in pragmatic terms, and we insist that language in use theory and speech act theory are a different theoretical frame, which differs from ours.

(3) Riestra, Dora. (2007). "Human communication as a semiotic object, a task at study". At Oficios Terrestres, School of Journalism and Social Communication, National University of La Plata. No. 19, year XIII. Available at https://sites.google.com/site/grupoeise/publicaciones

We consider this research paper as fundamental background for our own work given that it has as its object of study human communication and language. It approaches the notions language and human reasoning in its socio-historical derivations: Humboldt, Sapir, Sapir-Whorf. Riestra wrote this work for the School of Journalism and Social Communication, National University of La Plata in the same year that we attended the seminar "Socio-discursive interactionism" for our $\mathrm{PhD}$ in Communication.

The main aim of her work is to analyze its object-human communication—from the frame of the philosophical origin of language at its representational level. In this sense, it is different from our work, which will not only be focused on cognitive aspects; therefore, our concern about reasoning-language is secondary.

In the second part, her work revises Saussurean language theories in order to infer "bad" readings of them that have taken place, in particular, as regards Course of General Linguistics. We find it very interesting as an analysis of language theories.

Finally, the part of the paper that most agrees with our own research is the one related to the presentation of socio-discursive interactionism theories and of language as a form of human mediated action:

Language action is at the same time the place and the medium of social interaction which is constitutive of all human knowledge; it is in this practice that we elaborate discursive worlds which organize and semiotize social representations of the world; in the resulting intertexuality of this practice, collective wisdom is reproduced and kept, and it is in this confrontation with this socio-historical intertextuality that humans take and interiorize (Vigotsky) the representations that are at hand for any human agent. (Bronckart, 1997, p. 62)

(4) Vásquez Arrieta, Tomás. (2009). “Communication, language and pedagogy: A view from mediations”. At: SCielo, $\quad$ Folios, $\quad$ No. $29 \quad$ Bogotá Jan./June 2009. Available at http://www.scielo.org.co/scielo.php?script=sci_arttext\&pid=S0123-48702009000100003\&nrm=iso\&tlng=pt

What is original about this work is thinking on pedagogy and language from the concept of mediated action, for which the author makes a revision of the philosophical tradition (Ricoeur, 2001) to center on the phenomenological frame of Merleau-Ponty.

At some point this works focuses on the mediation of the media, from Martin Serrano's (1997) theories: 
The media creates representations of what happens and they are constrained by a double tension: on the one hand, there is the existing tension between the need of reproduction of the social order and its changes and transformations, which should be registered by the media. On the other hand, there is the existing tension between the typical unpredictability of what happens and the need to make it fit in the formats and languages with which the media expresses it. As the media faces these tensions, far away from deliberately reproducing reality as it is, it mediates its productions between culture, politics and the economy in order to elaborate a type of representation of that reality compatible with the system needs. In this light, Martin Serrano identified two types of mediation in the production of representations which the media makes. (as cited in Vásquez Arrieta, 2009)

Then the paper focuses on the studies of Jesús Martín Barbero (2002) as a conclusion of this previous genealogy to give account of the mediations for and by language.

We try to think, in the future, about the relation between mediation, language, and interactionism: in which aspects they coincide, are apart or integrated.

(5) Miranda Calderón, Luis Alfredo. (2011). “Language: Something more than a mechanism of communication”. At: Journal for Latin-America and the Caribbean, Educnre Electronic Journal, Vol. XV, No. 1, January-June. National University. Heredia, Costa Rica. Pages 161-170. Available at http://www.redalyc.org/redalyc/pdf/1941/194118804013.pdf

These authors study the relation between language and reasoning and its impact in the education field, in particular at school as regards the teaching of Spanish. Furthermore, they study how the access to the school curriculum is mediated by language.

Their original point of view is thinking on language from neuroscience (Ratey, 2003). They also adopt Vigotsky's theories but they do not work on them in deep.

Our object of study is immersed in the frame of Vigotsky's theory of language and education; given that socio-discursive interactionism adopts those notions. In this sense, our point of view is different from the one of neuroscience, and it is imbibed in a social view on language in relation to education as regards the training of Communication teachers and Language and Literature teachers.

(6) Montecinos, Jennifer Peralta. (2000). "Language acquisition and development and communication: A pragmatic constructivist view centered on contexts”. At: REDALYC, Límite, No. 007. University of Tarapacá. Arica, Chile. Pages 54-66. Available at redalyc.uaemex.mx/pdf/836/83600704.pdf

This research work is focused on language acquisition as communicative behavior. The authors revise pragmatic theory, the use and the importance of the contexts in language and talking acquisition, development and adaptation. They work with a frame that adopts, in part, the theory of cognition of Humberto Maturana, from a bio-psycho-social view on language, which we conceptually share.

Our work does not focus on the processes of acquisition, which are more related to psycholinguistics. Furthermore, we do not adopt a pragmatic frame given that it would have meant an epistemological choice which is different from the ones within the frame of socio-discursive interactionism, from which we stand.

(7) Castillo Vallejo. (2007). “Observation, communication and language”. At: Scielo, ALPHA No. 25, Dicember. Universidad de los Lagos. Talca, Chile. Pages 153-170. Available at http://www.scielo.cl/scielo.php?pid=S071822012007000200010\&script=sci_arttext

In this work, the relation between communication and language is analyzed in the frame of the theory of observation. 
The researcher is defined as a pragmatic distrubutionist, which means that this study is totally different from ours. Its conceptualizations as regards communication have their origin in the following theories: the (social) operationalization which the agent can do or develop on or around distinctions based on value criteria (aesthetic-moral), among other aspects. One of the topics that are not related to our object of study is the possibility of recognizing in language a media through which we can shade or hide the truth (Gadamer, 1998).

In the frame of socio-discursive interactionism, which we follow, truth values are not dealt with; though human action, which can be understood from collective activities as cooperation structures which organize individuals interactions with the environment are. Activities are several according to their general anthropological motivations (nutrition activities, defense activities, reproduction activities, etc.) or according to its structural properties in relation to the instrumental resources at disposal (Riestra, 2012).

(8) Flores Romero, Rita, Castro Martínez, Jaime, \& Arias Velandia, Nicolás. (2009). “Communication, language and education: A view from the theories of complexity”. At: SCielo, Folios, Segunda época, No. 30, Second half of the year. Pages 25-38. Available at http://www.scielo.org.co/pdf/folios/n30/n30a02.pdf

The authors of this work adopt the concept communicative interaction to develop the theory of complexity from complex thinking, more related to psycholinguistics, based on the concept of system. Said concepts explain three aspects of communicative interaction in education: knowledge structures, teacher-pupil relationship, and knowledge environments.

In education systems, according to their work, there are several ways in which the members of the system relate to each other, these differences being related to the relation between peers or the teacher-pupil relation. This interaction has an important role in the social and individual construction of students: "Such interchange is possible only through the understanding between them, in which one gives and the other receives and at the same time responds to the first, thus creating what we call communication" (Clark \& Chalmers, 1998, p. 10). We believe that the concept "communication" is strictly linked to the one of "conversation", and once again we resort to Pragmatics to analyze language phenomena, but we are not going to refer to it in the theoretical frame we have adopted.

\section{Conclusion}

In order to finish, it is notorious that all research works done in the state of the art do not show evident relations between language and communication and even less evident they are in the theoretical-methodological frame of socio-discursive interactionism. Furthermore, we hitherto have not found previous research works for the analysis of the teachers' training in Communication and in Language and Literature with focus on the relation communication/language at the National University of La Plata and Higher Institute of Teachers' Training, from the theoretical-methodological frame we propose.

We believe that in a future thesis, it is original to think on the relation between teaching courses in Language and Literature and in Communication. This first approach to the state of the art is a first sample and analysis of how the object of study was investigated; that is, the approaches to think about it and their methodologies, categories, and units of analysis that the previous works adopted. With the approach we have proposed, we have also started to better define the object of our research work and the invariant factors that affect it. As Samaja claimed (2003) "the universal can be conceived also as norm of a species, the structure of a system, and the 
invariant factors of a structure. There can only be few doubts about this issue: social sciences look for such invariant factors” (p. 34).

\section{References}

Bajtín, M. (1982). Aesthetics of verbal creation. México: Siglo XXI.

Bonckart, J.-P. (2004). Verbal activity, texts and discourses. For a socio-discursive interactionism. Madrid: Infancia y Aprendizaje Foundation.

Bourdieu, P. (Ed.). (2001). The logic of practice. Barcelona: Taurus.

Bronckart, J.-P. (1997). Activité langagiére, textes et discours (Language activity, texts and discourses). Paris-Genéve: Delachaux et Niestle.

Bronckart, J.-P. (2007). Language development and language. Didactics. Buenos Aires: Miño y Dávila.

Charaudeau, P., \& Maingueneau, D. (2005). Dictionary of discourse analysis. Buenos Aires: Amorrortu Editores.

Clark, A., \& Chalmers, D. J. (1998). The extended mind. Analysis, 58, 7-19. (Reprinted from Philosophy of mind: Classical and contemporary readings, by D. J. Chalmers, Ed., 2002, Oxford: Oxford University Press)

Coseriu, E. (1977). Man and his language. Madrid: Gredos.

De Lopes, V., \& Immacolata, M. (1999). Research in communication: Espistemological, theoretical and methodological aspects. Diálogos de la comunicación Magazine, (56), 12-27.

Edelstein, G. (2011). Training others and oneself in teaching. Buenos Aires: Paidós.

Foucault, M. (1979). The archaeology of knowledge. México: Siglo XXI Editores.

Gadamer, H. G. (1998). Truth \& method I \& II. Salamanca: SÍGUEME.

Gaitán Moya, J., \& Piñuel Raigada, J. (1996). Research techniques in social communication. Madrid, Spain: Síntesis.

General Bureau of Culture and Education. (2008). Retrieved from www.abc.gov.ar.

Habermas, J. (1987). Theory of communicative action I \& II. Madrid: Taurus.

National Institute of Teachers' Training. (2012). Retrieved from www.infd.edu.ar or http://portales.educacion.gov.ar/infd/

Ratey, J. (2003). The brain: Manual of instructions. Barcelona: De Bolsillo.

Ricoeur, P. (2001). Text to action. Buenos Aires: Fondo de Cultura Económica.

Riestra, D. (2008a, October). Language didactics between research and practices. Papers presented at First International Meetings of Research and Practices in Language and Literature Didactis, San Carlos de Bariloche, Argentina.

Riestra, D. (2008b, November). Problems of teachers' training: Revisiting languages grammars in texts. Papers presented at the First International Congress of Communicative Interaction and Language Teaching, Universitat de Valéncia, Valéncia, Spain.

Riestra, D. (2011). The training of language and literature teachers' and the education of textual genres. SCRIPTA, 15(28), 171-203.

Riestra, D. (2012). Description of a project (or proposal) for continuing education in Argentina en continuing education in action: the theoretical basis of technological field. Continuing education in Argentina in action: On the theoretical basis of domain technology. Bariloche: Unrío Negro.

Riestra, D. (Ed.). (2010). Historical and epistemological studies (F. Saussure, V. Voloshinov, \& M. Bajtín, Rev.). Buenos Aires: Miño y Dávila.

Samaja, J. (2003). Epistemology and methodology: Elements for a scientific research theory. Buenos Aires, Argentina: Eudeba.

Saussure, F. de. (1984). Course in general linguistics. Buenos Aires: Losada.

Tomasello, M. (2008). Origins of human communication. Cambridge: MIT Press.

Vigotsky, L. (2010). Thought and language (2nd ed.). Barcelona: PAIDOS IBERICA.

Voloshinov, V. N. (2009). The Marxism and the philosophy of language. Buenos Aires: Ediciones Godot Argentina. (First publication, 1929. Foreword and translation of Tatiana Bubnova) 